\title{
Prescription Pattern of ANTI-Hypertensive DRUgS in A TERTIARY HEALTH INSTITUTION IN NIGERIA
}

\author{
${ }^{1}$ E. Etuk, ${ }^{2}$ S. A. Isezuo, ${ }^{1}$ A. Chika, ${ }^{1}$ J. Akuche and ${ }^{1}$ M. Ali \\ ${ }^{1}$ Department of Pharmacology, College of Health Sciences Usmanu DanFodiyo University, Sokoto, Nigeria \\ ${ }^{2}$ Department of Medicine, College of Health Sciences Usmanu DanFodiyo University, Sokoto, Nigeria \\ Reprint requests to: Dr E.U. Etuk, Department of Pharmacology, College of Health Sciences, Usmanu Danfodiyo \\ University, Sokoto, C/o P.O. Box 2298, Sokoto. Nigeria E-mail: etuk2005@yahoo.co.uk, Tel.: +234-8054693770
}

\begin{abstract}
Objective: This study examined the pattern of physicians' prescription of antihypertensive drugs and its possible effects on blood pressure control as well as physicians' compliance with recommended guidelines.

Methods: Records of 145 patients aged 17-91 (mean: $52.6 \pm 14.6$ ) years, with male to female ratio of 1:1.2 were randomly selected. Information on antihypertensive prescriptions was recorded. Blood pressure control was defined as systolic and diastolic blood pressure less than $140 \mathrm{~mm} \mathrm{Hg}$ and $90 \mathrm{mmHg}$, respectively.

Results: Of the 145 patients studied, 20\% (29) were on monotherapy and $80 \%$ (116) on combination therapy. Of the patients on combination therapy, 61.2\% (71), 33.6\% (39) and 5.2\% (6) were on 2, 3 and 4 drugs, respectively. Diuretic was the most frequently prescribed drug either as a single agent (44.8\%) or as combination therapy (88.8\%). Mean reductions in both systolic and diastolic blood pressures were more in patients on calcium channel blocker than those on diuretic monotherapy $(t=2.5$ and 3.6 for reductions in systolic and diastolic $B P$, respectively; $P<.05$ for both), and, in patients on combination therapy than those on monotherapy $(t=3.64$ and 3.27 for reductions in systolic and diastolic BP, respectively; $P<.01$ for both). Blood pressure control rate was $30.5 \%$.

Conclusion: Our results are consistent with the previously observed benefits of antihypertensive combination therapy, and demonstrate an apparent higher efficacy of calcium channel blocker monotherapy than diuretic monotherapy in blood pressure lowering in the study population. Major limitations of this work include its retrospective nature and the inability to determine the actual patients' adherence to therapy.
\end{abstract}

Key words: Antihypertensive, prescription, blood pressure control

Résumé

Objectif: Cette étude a examiné le schéma de l'ordonance médicale (prescription médicamenteuse) des antihypertenseurs et son effet possible dans le contrôle de l'hypertension artérielle ainsi que sa comformité aux indications recommendées.

Methode: Les données de 145 patients âgés de 17 à 91 ans, (moyenne: 52, 6+ 14, 6) avec un rapport d'un homme pour 1, 2 femmes, ont été recueillis au hazard. Des informations sur les ordonnances des antihypertenseurs ont été enregistrées. Moins de $140 \mathrm{~mm} / \mathrm{hg}$ pour systolique et $90 \mathrm{~mm} / \mathrm{hg}$ pour diastolique ont été retenus comme le contrôle.

Resultats: De 145 partients études, 20\% soit patients étaient sur le régime monothérapie (combinée). Pour les patient en régime multithérapie, $61,2 \%$ soit $71,33,6 \%$ soit 39 et $5,2 \%$ soit 6 étaient sur 2,3 , et 4 médicaments respectivement. Les diurétiques étaient plus fréquemment prescript, soit seuls (44, 
$8 \%$ ) ou en combinaison avec d'autres agents antihypertenseurs. La réduction moyenne dans les deux cas de systolique et diastolique était plus élevée chez les patients prenant les diurétiques tout court. (= 2.5 et, 3.6 pour la réduction en systolique et diastolique respectirement; $p<0.05$ pour les deux cas), et chez les patients en thérapie combinée que chez ceux en monothérapie $(t=3,64$ et 3,27 pour la réduction en systolique et diastolique respectivement; $p<0.01$ ) pour les deux cas_. Le taux de contrôle était 30, 5\%.

Conclusion: Nos résultats correspondent aux bénéfices déjà observés dans le régime de la thérapie antihypertensive combinée, et montre une efficacité clairement élevée de beta-bloquants de calcium (la chaine de bloquants de calcium) utilisés en monothérapie que les diurétiques utilisés en monothérapie dans l'abaissement de la tension artérielle au sein de l'échantillon de l'étude.

Mots clés: Antihypertensif, prescription, commande de tension artérielle

\section{Introduction}

Despite the availability of a wide range of antihypertensive drugs, hypertension and its complications are still important causes of adult morbidity and mortality in sub-Saharan Africa ${ }^{1,2}$. More than $50 \%$ of treated hypertensive patients have a blood pressure level greater than 140/90 mm Hg (uncontrolled hypertension) ${ }^{3,4}$. Several factors including, among others, poor adherence to therapeutic regimen, ignorance, and poverty ${ }^{3-5}$ have been adduced for the high prevalence of uncontrolled hypertension. Recent reports have however focused on the role of health care provider to poor adherence to antihypertensive drugs ${ }^{6,7}$. Consequently, compliance with standard guidelines aiding physicians in effective prescription of antihypertensive drugs have been emphasized ${ }^{8}$. This study is aimed at determining the physicians' prescription pattern of antihypertensive medications in a tertiary health institution in northwestern Nigeria. Physicians' compliance with the existing guidelines is described.

\section{Materials and Methods}

This is a retrospective cross-sectional study done between 4th May and 2nd June 2006, in Usmanu Danfodiyo University Teaching Hospital, Sokoto, Nigeria. Records of 181 patients aged between 1791years (mean: $52.6 \pm 14.6$ ) with a male to female ratio of $1: 1.2$ were selected by simple random sampling technique using table of random numbers. Thirty six clinical records were excluded due to incomplete data. Of the remaining 145 patients studied, 14 who died on admission from complications of hypertension were also excluded from the calculation of treatment outcomes including blood pressure control and adherence rates.

Demographic and clinical information including age, gender, documented blood pressure at the time of first clinic attendance or admission, blood pressure at subsequent visits, and the anti-hypertensive medications were recorded. Prescription of a drug with fixed dose combination was considered as monotherapy. Blood pressure control was defined as the maintenance of blood pressures values less than $140 / 90 \mathrm{~mm} \mathrm{Hg}$ during at least two successive appointments. ${ }^{4,8}$ Adherence to drug regimen was assessed in the in-patients using patients drug charts. Patients taking at least $80 \%$ of the prescribed tablets were considered adherent. In case of the outpatients, clinic adherence was determined using compliance with outpatient clinic appointments. ${ }^{4}$ The last 4 scheduled clinic visits were assessed. Patients with $75 \%$ clinic attendance were regarded as clinic adherent, while patients with $<75 \%$ attendance were recorded as non-adherent. ${ }^{4}$ Different grades of hypertension were defined using the 1999 WHO-ISH guidelines. ${ }^{9}$

Data analysis was done using the statistical program for the social sciences (SPSS) software. Continuous data are presented as mean \pm standard deviation, while categorical data are presented as percentages. Differences between means of two groups were compared using student's $t$ test, while that between proportions were compared using $\chi^{2}$ test. A p-value less than 0.05 was considered as significant.

\section{Results}

The mean age of patients was $52.3 \pm 14.6$ years. Of the 145 patients studied, $53.8 \%$ and $46.2 \%$ were females and males, respectively. The most frequent grade of hypertension among the patients was severe hypertension (35.9\%). Mild hypertension, moderate hypertension, and isolated systolic hypertension were observed in $29.0 \%, 29.0 \%$ and $5.5 \%$ of the patients respectively. The patterns of antihypertensive prescriptions are shown in Table 1. Of the 145 patients studied, 29 (20\%) were on monotherapy, while 116 (80\%) were on combination therapy. Of the 116 patients on combination therapy, $71(61.2 \%), 39$ (33.6\%) and 6 (5.2\%) were on 2, 3 and 4 drugs, respectively. The most frequently 
prescribed antihypertensive is diuretic either singly $(44.8 \%)$ or in combination with other antihypertensive drugs (88.8\%). Two drug combinations appear to be the most frequent. It was prescribed in $26.8 \%, 38.0 \%$ and $29.6 \%$ of patients with mild, moderate and severe hypertension respectively. Monotherapy and 3 or 4 drug combinations were mainly prescribed for patients with mild (58.6\%) and severe (68.9\%) hypertension, respectively.

The baseline blood pressure tend to be higher as the number of drugs prescribed increases with the mean baseline blood pressures for patients on monotherapy and combination therapy being $154.8 \pm 8.3 / 95.5 \pm 9.1$ and $175.6 \pm 32.8 / 109.5 \pm 18.7$ $\mathrm{mm} \mathrm{Hg}$, respectively $(P<.05$ for both systolic and diastolic blood pressures) (Table 2). Patients on combination therapy achieved significantly higher reduction in systolic and diastolic blood pressures compared to those on monotherapy $(15.4 \pm 17.0 / 7.0 \pm 8.2$ vs. $32.6 \pm 26.6 / 18.7 \pm 14.9 \mathrm{~mm}$ $\mathrm{Hg} ; \quad P<.05$ for reductions in both systolic and diastolic blood pressures) (Table 2). However, further use of 3 or 4 drugs was not associated with significant benefit over 2 drug combinations in terms of reduction in blood pressures $(P>.05$ for both systolic and diastolic blood pressure reductions).

There was no significant difference in baseline blood pressures of patients on calcium channel blocker monotherapy and those on diuretic monotherapy (Table 3). However, calcium channel blocker monotherapy significantly lowers blood pressures more than diuretic monotherapy $(28.6 \pm 16.8 / 12.9 \pm 5.7$ vs. $11.7 \pm 7.1 / 4.4 \pm 3.0 \mathrm{~mm} \mathrm{Hg}$; $P<.05)$. Satisfactory blood pressure control was achieved in 40 (30.5\%) patients.

The co-morbid conditions that were documented among the study population included diabetes mellitus (26.9\%), cardiac failure (17.9\%), renal disease (15.2\%) and stroke (10.0\%). Diuretic, either alone or in combination with other antihypertensives, was the most frequently used drug in these groups of patients, the frequency of use being $100 \%, 91.7 \%, 85.7 \%$ and $61.5 \%$ of hypertensive patients with cardiac failure, renal disease, stroke, and diabetes mellitus, respectively. Angiotensin converting enzyme inhibitors (ACEIs), either singly or as part of combination therapy were the second most frequently prescribed drugs in hypertensive patients with co-morbid conditions. It was prescribed in $69.2 \%, 54.5 \%, 53.8 \%$, and $14.3 \%$ of hypertensive patients with heart failure, renal disease, diabetes mellitus, and stroke, respectively.

Table 1. Pattern of prescription of antihypertensive drug

\begin{tabular}{ll}
\hline Drug regime & No (\%) \\
\hline (i) Monotherapy & $13(44.8)$ \\
D & $8(27.6)$ \\
C & $5(17.2)$ \\
A & $3(10.4)$ \\
Alpha methyldopa & \\
(ii) 2 drug Combinations & $28(24.1)$ \\
A + D & $16(13.8)$ \\
Alpha methyldopa + D & $14(12.1)$ \\
C + D & $6(5.2)$ \\
A + C & $5(4.3)$ \\
Alpha methyldopa + C & $1(0.9)$ \\
Valsartan + C & $1(0.9)$ \\
Hydrallazine + A & \\
(iii) 3 drug combinations & $20(17.2)$ \\
Alpha methyldopa + A + D & $6(5.2)$ \\
A + C + D & $5(4.3)$ \\
Alpha methyldopa + C + D & $4(3.4)$ \\
A + B + D & $3(2.6)$ \\
B + C + D & \\
(iv) 4 drug combinations & $4(3.4)$ \\
Alpha methyldopa+ A + C + D & $1(0.9)$ \\
Alpha methyldopa + B + C + D & $1(0.9)$ \\
Hydrallazine + Alpha methyldopa \\
$+\quad$ \\
A+ D & \\
\hline A Angiotensin convertingenzyme inhibitor & B: Beta \\
\hline
\end{tabular}

A: Angiotensin converting enzyme inhibitor; B: Beta blocker; C: Calcium channel blocker; D: Diuretic

Table 2. Comparison of patients on monotherapy and combination therapy

\begin{tabular}{lllll}
\hline $\begin{array}{l}\text { Blood pressure } \\
(\mathbf{m m H g})\end{array}$ & $\begin{array}{l}\text { Monotherapy } \\
(\mathbf{n}=\mathbf{2 9})\end{array}$ & $\begin{array}{l}\text { Combination } \\
\text { therapy }(\mathbf{n}=\mathbf{1 1 6})\end{array}$ & t-value & p-value \\
\hline Baseline mean SBP & $154.83 \pm 8.29$ & $175.60 \pm 32.79$ & 6.09 & $<0.001$ \\
Baseline mean DBP & $95.52 \pm 9.10$ & $109.48 \pm 18.74$ & 5.76 & $<0.001$ \\
Mean reduction in SBP & $15.43 \pm 16.98$ & $32.64 \pm 26.60$ & 3.64 & $<0.001$ \\
Mean reduction in DBP & $6.96 \pm 8.22$ & $18.66 \pm 14.91$ & 3.27 & $<0.01$ \\
\hline
\end{tabular}

SBP: Systolic blood pressure; DBP: Diastolic blood pressure 
Table 3. Comparison of patients on calcium channel blocker monotherapy and diuretic monotherapy

\begin{tabular}{lllll}
\hline Blood pressure $(\mathbf{m m H g})$ & $\begin{array}{l}\text { CCB monotherapy } \\
(\mathbf{n}=\mathbf{8})\end{array}$ & $\begin{array}{l}\text { Diuretic monotherapy } \\
(\mathbf{n}=\mathbf{1 3})\end{array}$ & t- value & p-value \\
\hline Baseline mean SBP & $157.5 \pm 7.07$ & $154.62 \pm 9.67$ & 0.73 & $>0.05$ \\
Baseline mean DBP & $95 \pm 10.69$ & $98.46 \pm 6.89$ & 0.76 & $>0.05$ \\
Mean reduction in SBP & $28.57 \pm 16.76$ & $11.67 \pm 7.07$ & 2.50 & $<0.05$ \\
Mean reduction in DBP & $12.86 \pm 5.67$ & $4.44 \pm 3.00$ & 3.56 & $<0.01$ \\
\hline
\end{tabular}

SBP: Systolic blood pressure; DBP: Diastolic blood pressure; CCB: Calcium channel blocker

\section{Discussion}

The proportion of patients on combination therapy in the current report $(80 \%)$ is consistent with the value of $73 \%$ found in Ibadan, ${ }^{10}$ but higher than $56 \%$ reported by Isezuo and Njoku in Sokoto. ${ }^{6}$ The high prescription rate of combination therapy may be due to the high prevalence of patients with severe and moderate hypertension, and the presence of comorbid diseases, particularly diabetes mellitus. These findings are consistent with the recent trends advocating the use of combination therapy as a first line treatment. ${ }^{10-12}$ Our observation that patients on combination therapy had significantly higher reduction in systolic and diastolic blood pressures than those on monotherapy further confirm the previously described benefits of antihypertensive combination therapy.

The choice of diuretic as the first line antihypertensive drug is consistent with other reports from Nigeria, 10, 13, 14 and in compliance with the current national ${ }^{15}$ and JNC VII guidelines. ${ }^{8}$ However, contrary to the traditional recommendations in most guidelines including the report of Antihypertensive and Lipid-Lowering treatment to prevent Heart Attack Trial (ALLHAT), ${ }^{16}$ calcium channel blocker was found to lower blood pressures more than diuretic when both were used as monotherapy. Though this finding is consistent with the reports of some other trials involving blacks, ${ }^{17}$ it needs to be confirmed in a study involving a larger population.

We observed low frequency of prescription of ACEI or centrally acting agent such as alpha methyldopa as monotherapy. Furthermore, none of the patients in the study population was on betablocker monotherapy. These patterns of prescription agree with the traditional recommendations that neither ACEI nor beta-blocker monotherapy is effective in blacks. ${ }^{15}$ The adverse effects of centrally acting antihypertensive agents have also been well described. ${ }^{18}$ The frequency of prescription of ACEI was however high, in patients with co-morbid conditions. The benefits of ACEI in preventing cardiovascular events and target organs disease in patients with diabetes mellitus, heart failure, hypertensive renal insufficiency and diabetic nephropathy have been documented. ${ }^{19}$
The blood pressure (BP) control rate of $30.5 \%$ in the current report is similar to the value of $29 \%$ obtained in Ibadan ${ }^{10}$ and the world wide epidemiological data showing fewer than $1 / 3$ of the hypertensive patients achieve blood pressure control. ${ }^{8}$ Non-adherence ${ }^{20}$ to treatment is the dominant factor contributing to inadequate BP control. In the current report we were unable to determine the actual drug adherence. It has been previously observed that blood pressure control rate is higher among clinic appointment compliant patients than the non-compliant ones. ${ }^{4}$ Hence, low compliant rate with clinic appointment suggests that poor compliance to medication might have contributed to poor blood pressure control in the current report. We however recognized that clinic attendance does not necessarily imply adherence.

It has also been previously observed that in spite of the benefits of combination therapy, too many drug combinations may adversely influence patients' adherence and blood pressure control. ${ }^{19}$ This may explain the apparent lack of significant further blood pressure reduction observed among patients on 3 or more drugs compared to those on 2 drug combinations in the current report. In conclusion, our results show that the choices of antihypertensive drugs reasonably comply with the national and international guidelines on the management of hypertension. The benefit of combination therapy over monotherapy as well as possible better efficacy of calcium channel blocker over diuretic in the study population was demonstrated. A major limitation of this work is its retrospective nature. Actual adherence could not be determined.

\section{References}

1. Isezuo SA, Omotoso ABO, Gaye A, Corrah T, Araoye MA. One year survival among subSaharan Africans with hypertensive heart failure. Tropical Cardiology. 2000; 26:57-60.

2. Cappuccio FP, Micah FB, Emmett L, et al. Prevalence, detection, management and control of hypertension in Ashanti, West Africa. Hypertension. 2004; 43:1017-1022.

3. Salako BL, Ajose FA, Lawani E. Blood pressure 
control in a population where antihypertensives are given free. East Afr Med J. 2003; 80:529-531.

4. Isezuo AS, Njoku $\mathrm{CH}$. Blood pressure control among hypertensives managed in a specialized health care setting in Nigeria. Afr J Med Med Sci. 2003; 32:65-70.

5. Isezuo SA, Opara TC. Hypertension awareness among Nigerian hypertensives in a Nigerian tertiary health institution. Sahel Medical Journal. 2000; 3:93-97.

6. Hyman DJ, Pavlik VN. Characteristics of patients with uncontrolled hypertension in the United States. N Engl J Med. 2001; 345:479-486.

7. Ren XS, Kazis LE, Lee A, Zhang $H$, Miller DR. Identifying patient and physician characteristics that affect compliance with antihypertensive medications. J Clin Pharm Ther. 2002; 27:47-56.

8. The seventh report of the joint national committee on prevention. Detection, evaluation, and treatment of high blood pressure (the JNC 7 report). JAMA. 2003; 289:2560-2571.

9. Guidelines Subcomittee. World Health Organization (WHO)/International Society of Hypertension (ISH) guidelines for the management of hypertension. J Hypertens. 1999; 17:151-185.

10. Yusuff KB, Balogun OB. Physicians' prescribing of antihypertensive combinations in a tertiary care setting in southwestern Nigeria. J Pharm Pharm Sci. 2005a; 8:235-242.

11. Neutel JM. The role of combination therapy in the management of hypertension. Oxford Journals. Nephrol Dial Transplant. 2006; 21:1469-1473.

12. Gavras I, Rosenthal T. Combination therapy as first-line treatment for hypertension. Curr Hypertens Rep. 2004; 6:267-272.

13. Adigun AQ, Ishola DA, Akintomide AO, Ajayi AAL. Shifting trends in pharmacologic treatment of hypertension in a Nigerian tertiary hospital: a
14. real world evaluation of the efficacy, safety, rationality and pharmacoeconomics of old and new antihypertensive drugs. J Hum Hypertens. 2003; 17:277-285.

15. Yusuff KB, Balogun OB. Pattern of drug utilization among hypertensives in a Nigerian teaching hospital. Pharmacoepidemiol Drug Saf. 2005b; 14:69-74.

16. Guidelines Committee of the Nigerian Hypertension Society. Guidelines for the management of hypertension in Nigeria. Nigerian Hypertension Society. 2005.

17. The ALLHAT Officers and Coordinators for the ALLHAT Collaborative Research Group. Major outcomes in high-risk hypertensive patients randomized to angiotensin-converting enzyme inhibitor or calcium channel blocker vs. diuretic: The Antihypertensive and Lipid-Lowering treatment to prevent heart attack trial (ALLHAT). JAMA. 2002; 288:2981-2997.

18. Centre for Reviews and Dissemination, University of York. Effectiveness of antihypertensive drugs in black people. Eff Health Care. 2004; 8:1-12.

19. Douglas JG, Bakris GL, Epstein $M$, et al. Management of high blood pressure in African Americans: consensus statement of the Hypertension in African Americans. Working Group of the International Society on Hypertension in Blacks. Arch Intern Med. 2003; 163:525-541.

20. Guidelines Committee ESH-ESC. 2003 European Society on Hypertension-European Society of Cardiology guidelines for the management of arterial hypertension. J Hypertens. 2003; 21:1011-1053.

21. Yiannakopoulou ECh, Papadopulos JS, Cokkinos DV, Mountokalakis TD. Adherence to antihypertensive treatment: a critical factor for blood pressure control. Eur J Cardiovasc Prev Rehabil. 2005; 12:243-249. 